\title{
Editorial
}

\section{Control of Vector-Borne Human Parasitic Diseases}

\author{
Fernando A. Genta, ${ }^{1,2}$ Hector M. Diaz-Albiter, ${ }^{3,4}$ Patrícia Salgueiro, $^{5}$ and Bruno Gomes ${ }^{6}$ \\ ${ }^{1}$ Oswaldo Cruz Institute-Oswaldo Cruz Foundation (IOC-FIOCRUZ), Av. Brasil 4365, Manguinhos, \\ 21040-360 Rio de Janeiro, RJ, Brazil \\ ${ }^{2}$ National Institute of Science and Technology for Molecular Entomology (INCT-EM), Av. Carlos Chagas Filho 373, \\ Centro de Ciências da Saúde, Bloco D-SS, Sala 05, Cidade Universitária, RJ, Brazil \\ ${ }^{3}$ Wellcome Trust Centre for Molecular Parasitology, University of Glasgow, University Place, Glasgow G12 8TA, UK \\ ${ }^{4}$ Centro de Investigación y Estudios en Salud Animal, Facultad de Medicina Veterinaria y Zootecnia, \\ Universidad Autónoma del Estado de México, Av. Instituto Literario No. 100 Oriente, Col. Centro., 50000 Toluca, MEX, Mexico \\ ${ }^{5}$ Unidade de Parasitologia Médica, Global Health e Tropical Medicine, GHTM, Instituto de Higiene e Medicina Tropical, \\ IHMT, Universidade Nova de Lisboa, Rua da Junqueira 100, 1349-008 Lisbon, Portugal \\ ${ }^{6}$ Department of Vector Biology, Liverpool School of Tropical Medicine, Pembroke Place, Liverpool L3 5QA, UK
}

Correspondence should be addressed to Fernando A. Genta; gentafernando@gmail.com

Received 3 October 2016; Accepted 4 October 2016

Copyright (c) 2016 Fernando A. Genta et al. This is an open access article distributed under the Creative Commons Attribution License, which permits unrestricted use, distribution, and reproduction in any medium, provided the original work is properly cited.

Vector-borne diseases (VBD) transmitted by arthropods are responsible for over 1 billion cases and 1 million deaths every year, corresponding to at least $17 \%$ of all infectious diseases in human populations [1]. Among them, we can find malaria, leishmaniasis, onchocerciasis, lymphatic filariasis, Chagas disease, and African trypanosomiases, as well as several arboviral diseases (arthropod-borne virus) such as dengue and Zika virus. Some of these have reemerged in new parts of the world and have become a topic of growing importance in public health and in political and scientific agendas [2]. Several factors are contributing towards the reemergence of VBDs. On the one hand, the spread of resistance to drugs in pathogens has become a major obstacle for the effective treatment of some VBDs [3], and the emergence of new strains of arboviruses (e.g., Zika virus in Brazil) has created new challenges for health care systems [4]. On the other hand, an increase in insecticide resistance is threatening the sustainability of vector control programmes in several tropical regions [5]. Additionally, the expansion of different vector populations due to climate change is becoming a growing concern in temperate countries, where vector control programs have been discontinuous for almost 50 years $[6,7]$. The scientific community has been trying to overcome these challenges by creating new strategies and tools to improve the diagnosis and treatment of VBDs and by developing new methodologies and targets for vector control campaigns. This special issue of BioMed Research International compiles nine topical articles that explore recent advances in research of an eclectic range of pathogens, vectors, and human diseases affecting several regions of the world.

Malaria remains the human parasitic disease with the highest burden and with risk of reemergence in several areas worldwide. In this special issues there are four papers regarding malaria.

Dahalan et al. [8] focus on a promising target for antimalarial drug, the mitogen-activated protein kinase 2 (PfMAP2) and describe for the first time its activity, function, and expression throughout the cycle of the main malaria parasite Plasmodium falciparum.

Degarege and Erko [9] summarize the findings of epidemiological studies of Plasmodium and helminth coinfection, emphasizing the impact of the coinfection on malaria in a review article.

Mbengue et al. [10] present the results of an IgG binding assay able to discriminate the outcome of cerebral malaria 
cases in Senegal, with the prospect of a potential functionalassociated assay for symptomatic malaria analysis.

Finally, Ivanescu et al. [11] discuss the association between increasing rates of malaria over a time period where environmental temperature is also increasing. Based on an extrapolation of the climate conditions they predict the risk of malaria re-emergence in Romania.

Aedes aegypti is one of the most important disease vectors in the world. Its control is the main tool available to fight transmission of diseases such as dengue, Zika, or chikungunya. Bellinato et al. [12] bring us an overview of the resistance profile of $A$. aegypti to several insecticides in Brazil, the country most affected currently by dengue and Zika virus.

Presently, lice infestations occur worldwide despite great efforts to maintain high standards of public health. Infectious diseases transmitted by lice remain a public health concern in populations living in crowded and unsanitary conditions, a matter of great concern regarding refugee care. Sangaré et al. [13] detail a state-of-the-art review on the "Management and Treatment of Human Lice," which, like for many other vectors, have been highly affected by insecticide resistance.

Leishmaniasis in the Old and New World is transmitted via the bite of phlebotomine sand flies and is caused by kinetoplastid parasites belonging to the genus Leishmania. This collective group of diseases is distributed in 88 countries around the globe with up to 1.6 million estimated cases per year [14-16]. To date, there is no human vaccine and treatment is largely based in 1940's antimony-based drugs which use causes distressing side effects. To date, control of transmission of leishmaniasis has focused mainly on the use of insecticides, a strategy that will eventually result in selection of resistant strains of insects, as seen in other insect vectors, such as Aedes aegypti and Anopheles spp. The World Health Organization has emphasized the need of developing novel strategies and research on these neglected vectorborne diseases. This special issue includes two papers on leishmaniasis.

Hijjawi et al. [17] assessed the use of molecular tools for the study of human leishmaniasis cases in Jordan, showing that identification of parasite species from dry samples is possible and improves clinical diagnosis. Besides that, they report the occurrence of Leishmania tropica in Jordan, which could be a new epidemiological concern related to the Syrian crisis.

Mohamed Mahmoud et al. [18] identified the presence of Leishmania major and L. tropica in a cutaneous leishmaniasis foci in Errachidia, Morocco, using molecular techniques. The authors also discuss the geographical distribution of Leishmania spp. in this area and report, for the first time, the presence of L. tropica in the region.

Chagas disease is still a major parasitic disease in the Americas, with up to 7 million cases worldwide. It has gained recent attention due to imported cases in nonendemic regions like USA (>300,000 cases) or Europe (>80,000 cases) [19]. It is caused by the parasite Trypanosoma cruzi, which is transmitted by the feces and urine of triatomine kissing bugs. The resurgence of vector populations and some reports of insecticide resistance in triatomines make of special interest the study and development of new strategies for control of these vectors [20]. Henriques et al. [21] studied in detail the action of the Insect Growth Regulator (IGR) Triflumuron (TFM) in Rhodnius prolixus, which is a model for triatomine biology. This work shows important effects of TFM on female fertility and gives some new insights in the mechanism of action of this insecticide, as impairments in diuresis and chitin turnover with reflections in insect immunity.

Taken together, the articles in this special issue cover several important aspects of major VBDs, highlighting not only their impact in human health, but also their significance for the development of new concepts and tools for the medical and biological research.

Tribute to Dr. Bruce Alexander. During our time as guest editors for this special number, we lost our friend and colleague John Bruce Alexander, who sadly passed away last March after a quiet battle against cancer. Bruce worked extensively in countries such as Colombia, Ecuador, and Brazil, being an international reference in the field of sampling and control of phlebotomine sandflies. Besides contributing with essential reviews and discussions to the field of leishmaniasis [22-25], he participated in seminal works related to the most diverse topics related to this neglected tropical disease, including transmission by midges in Australia [26], insecticide use and resistance in sandflies [27-30], role of chickens [31, 32], dogs $[33,34]$, and plants $[35,36]$ in the maintenance of vectors and parasite life cycle, taxonomic description of new sand fly species [37, 38], sand fly sex pheromones [39, 40], RNAi in sand flies [41], and biological control of sand flies [42]. His work relates to current and successful interventions for disease control, especially in the New World. Because his contribution to this special issue was interrupted in the presubmission stage, we decided to honor him with a very short obituary note here.

Bruce graduated in biology in the University of Edinburgh in 1979 and got his M.S. degree in entomology in the University of London. In his time there, Bruce met Dr. Robert Killick-Kendrick, who introduced him to the study of sand flies. A few years later, Bruce carried out a Ph.D. degree in Florida University on the ecology of sand flies in Northeast Colombia, learning Spanish and Portuguese and working on different aspects of phlebotomine biology. Later he moved to Brazil, where he worked at the Universidade Federal de Minas Gerais and FIOCRUZ. He moved back to the UK and in 2005 started working at the Liverpool School of Tropical Medicine. Later in his professional life, Bruce decided to become an independent researcher and together with his wife Cristina, he successfully started Xeroshield Ltd. in 2005 and Garrapat Ltd. in 2015. The spirit of both companies was to offer "practical solutions to insect control and vector-borne disease prevention to offer safe, sustainable, environmentally friendly alternatives to chemical pesticides." He was an enthusiastic ornithologist, as well. He is survived by his wife, Cristina, and his son, Patrick. We will dearly miss his sense of humor, his wit, and passionate and argumentative discussions. 


\section{Acknowledgments}

We would like to thank our contributors for their manuscripts and the several anonymous expert reviewers that generously gave some of their time to assess all the manuscripts submitted.

\section{Fernando A. Genta \\ Hector M. Diaz-Albiter \\ Patrícia Salgueiro \\ Bruno Gomes}

\section{References}

[1] World Health Organization (WHO), "Vector-borne diseases," http://www.who.int/mediacentre/factsheets/fs387/en/.

[2] World Health Organization (WHO), WHO-A Global Brief on Vector-Borne Diseases, World Health Organization, Geneva, Switzerland, 2014.

[3] S. Takala-Harrison, C. G. Jacob, C. Arze et al., "Independent emergence of artemisinin resistance mutations among Plasmodium falciparum in Southeast Asia," Journal of Infectious Diseases, vol. 211, no. 5, pp. 670-679, 2015.

[4] G. Calvet, R. S. Aguiar, A. S. Melo et al., "Detection and sequencing of Zika virus from amniotic fluid of fetuses with microcephaly in Brazil: a case study," The Lancet Infectious Diseases, vol. 16, no. 6, pp. 653-660, 2016.

[5] H. Ranson, R. N'guessan, J. Lines, N. Moiroux, Z. Nkuni, and V. Corbel, "Pyrethroid resistance in African anopheline mosquitoes: what are the implications for malaria control?" Trends in Parasitology, vol. 27, no. 2, pp. 91-98, 2011.

[6] D. Fischer, S. M. Thomas, M. Neteler, N. B. Tjaden, and C. Beierkuhnlein, "Climatic suitability of aedes albopictus in europe referring to climate change projections: comparison of mechanistic and correlative niche modelling approaches," Eurosurveillance, vol. 19, no. 6, 2014.

[7] I. Rochlin, D. V. Ninivaggi, M. L. Hutchinson, and A. Farajollahi, "Climate change and range expansion of the asian tiger mosquito (Aedes albopictus) in northeastern USA: implications for public health practitioners," PLoS ONE, vol. 8, no. 4, Article ID e60874, 2013.

[8] F. A. Dahalan, H. M. Sidek, M. D. Murtey et al., "Phosphorylated and nonphosphorylated PfMAP2 are localized in the nucleus, dependent on the stage of plasmodium falciparum asexual maturation," BioMed Research International, vol. 2016, Article ID 1645097, 9 pages, 2016.

[9] A. Degarege and B. Erko, "Epidemiology of Plasmodium and helminth coinfection and possible reasons for heterogeneity," BioMed Research International, vol. 2016, Article ID 3083568, 6 pages, 2016.

[10] B. Mbengue, M. M. Fall, M. Sylla Niang et al., "Relationship between antibody levels, IgG binding to Plasmodium falciparum-infected erythrocytes, and disease outcome in hospitalized urban malaria patients from Dakar, Sénégal," BioMed Research International, vol. 2016, Article ID 5381956, 11 pages, 2016.

[11] L. Ivanescu, I. Bodale, S.-A. Florescu, C. Roman, D. Acatrinei, and L. Miron, "Climate change is increasing the risk of the reemergence of malaria in Romania," BioMed Research International, vol. 2016, Article ID 8560519, 7 pages, 2016.

[12] D. F. Bellinato, P. F. Viana-Medeiros, S. C. Araújo, A. J. Martins, J. B. Lima, and D. Valle, "Resistance status to the insecticides temephos, deltamethrin, and diflubenzuron in Brazilian Aedes aegypti populations," BioMed Research International, vol. 2016, Article ID 8603263, 12 pages, 2016.

[13] A. K. Sangaré, O. K. Doumbo, and D. Raoult, "Management and treatment of human lice," BioMed Research International, vol. 2016, Article ID 8962685, 12 pages, 2016.

[14] J. Alvar, I. D. Vélez, C. Bern et al., "Leishmaniasis Worldwide and Global Estimates of Its Incidence," PLOS ONE, vol. 7, no. 5, Article ID e35671, 2012.

[15] World Health Organization (WHO), Control of the Leishmaniases: Report of a Meeting of the WHO Expert Commitee on the Control of Leishmaniases, World Health Organization, Geneva, Switzerland, 2010.

[16] D. Sacks and S. Kamhawi, "Molecular aspects of parasite-vector and vector-host interactions in leishmaniasis," Annual Review of Microbiology, vol. 55, pp. 453-483, 2001.

[17] N. Hijjawi, K. A. Kanani, M. Rasheed, M. Atoum, M. AbdelDayem, and M. R. Irhimeh, "Molecular diagnosis and identification of leishmania species in jordan from saved dry samples," BioMed Research International, vol. 2016, Article ID 6871739, 7 pages, 2016.

[18] E. A. Mohamed Mahmoud, S. Faiza, M. Lemine et al., "Geographical distribution and new situation of leishmania species after the control of cutaneous leishmaniasis foci in errachidia province, Morocco, in 2014," BioMed Research International, vol. 2016, Article ID 8642373, 7 pages, 2016.

[19] J. R. Coura and P. A. Viñas, "Chagas disease: a new worldwide challenge," Nature, vol. 465, no. 7301, pp. S6-S7, 2010.

[20] G. C. D. Pessoa, P. A. Vinãs, A. C. L. Rosa, and L. Diotaiuti, "History of insecticide resistance of triatominae vectors," Revista da Sociedade Brasileira de Medicina Tropical, vol. 48, no. 4, pp. 380389, 2015.

[21] B. S. Henriques, F. A. Genta, C. B. Mello et al., "Triflumuron effects on the physiology and reproduction of Rhodnius prolixus adult females," BioMed Research International, vol. 2016, Article ID 8603140, 11 pages, 2016.

[22] R. Reithinger, J.-C. Dujardin, H. Louzir, C. Pirmez, B. Alexander, and S. Brooker, "Cutaneous leishmaniasis," Lancet Infectious Diseases, vol. 7, no. 9, pp. 581-596, 2007.

[23] R. Reithinger, P. G. Coleman, B. Alexander, E. P. Vieira, G. Assis, and C. R. Davies, "Are insecticide-impregnated dog collars a feasible alternative to dog culling as a strategy for controlling canine visceral leishmaniasis in Brazil?" International Journal for Parasitology, vol. 34, no. 1, pp. 55-62, 2004.

[24] B. Alexander and M. Maroli, "Control of phlebotomine sandflies," Medical and Veterinary Entomology, vol. 17, no. 1, pp. 1-18, 2003.

[25] B. Alexander, "Sampling methods for phlebotomine sandflies," Medical and Veterinary Entomology, vol. 14, no. 2, pp. 109-122, 2000.

[26] A. M. Dougall, B. Alexander, D. C. Holt et al., "Evidence incriminating midges (Diptera: Ceratopogonidae) as potential vectors of Leishmania in Australia," International Journal for Parasitology, vol. 41, no. 5, pp. 571-579, 2011.

[27] B. Alexander, V. C. Barros, S. F. De Souza et al., "Susceptibility to chemical insecticides of two Brazilian populations of the visceral leishmaniasis vector Lutzomyia longipalpis (Diptera: Psychodidae)," Tropical Medicine and International Health, vol. 14, no. 10, pp. 1272-1277, 2009. 
[28] B. Alexander, M. C. Usma, H. Cadena et al., "Evaluation of deltamethrin-impregnated bednets and curtains against phlebotomine sandflies in Valle del Cauca, Colombia," Medical and Veterinary Entomology, vol. 9, no. 3, pp. 279-283, 1995.

[29] B. Alexander, C. Jaramillo, M. C. Usma et al., "An attempt to control Phlebotomine sand flies (Diptera: Psychodidae) by residual spraying with deltamethrin in a Colombian village," Memórias do Instituto Oswaldo Cruz, vol. 90, no. 3, pp. 421-424, 1995.

[30] B. Alexander, H. Cadena, M. C. Usma, and C. A. Rojas, "Laboratory and field evaluations of a repellent soap containing diethyl toluamide (DEET) and permethrin against phlebotomine sand flies (Diptera: Psychodidae) in Valle del Cauca, Colombia," The American Journal of Tropical Medicine and Hygiene, vol. 52, no. 2, pp. 169-173, 1995.

[31] M. R. Sant'Anna, A. Nascimento, B. Alexander et al., "Chicken blood provides a suitable meal for the sand fly Lutzomyia longipalpis and does not inhibit Leishmania development in the gut," Parasites and Vectors, vol. 3, no. 1, article 3, 2010.

[32] B. Alexander, R. Lopes de Carvalho, H. McCallum, and M. H. Pereira, "Role of the domestic chicken (Gallus gallus) in the epidemiology of urban visceral leishmaniasis in Brazil," Emerging Infectious Diseases, vol. 8, no. 12, pp. 1480-1485, 2002.

[33] A. P. da Costa-Val, R. R. Cavalcanti, N. de Figueiredo Gontijo et al., "Canine visceral leishmaniasis: relationships between clinical status, humoral immune response, haematology and Lutzomyia (Lutzomyia) longipalpis infectivity," Veterinary Journal, vol. 174, no. 3, pp. 636-643, 2007.

[34] R. Reithinger, R. J. Quinnell, B. Alexander, and C. R. Davies, "Rapid detection of Leishmania infantum infection in dogs: comparative study using an immunochromatographic dipstick test, enzyme-linked immunosorbent assay, and PCR," Journal of Clinical Microbiology, vol. 40, no. 7, pp. 2352-2356, 2002.

[35] B. Alexander, L. A. Agudelo, J. F. Navarro et al., "Relationship between coffee cultivation practices in Colombia and exposure to infection with Leishmania," Transactions of the Royal Society of Tropical Medicine and Hygiene, vol. 103, no. 12, pp. 1263-1268, 2009.

[36] B. Alexander and M. C. Usma, "Potential sources of sugar for the phlebotomine sandfly Lutzomyia youngi (Diptera: Psychodidae) in a Colombian coffee plantation," Annals of Tropical Medicine and Parasitology, vol. 88, no. 5, pp. 543-549, 1994.

[37] C. B. Dossantos, A. Falqueto, and B. Alexander, "Description of three new species of nemapalpus (Diptera, Psychodidae, Bruchomyiinae) from atlantic forest in southeastern Brazil," Zootaxa, no. 2264, pp. 58-64, 2009.

[38] B. Alexander, J. M. Freitas, and L. W. Quate, "Some psychodidae (diptera) from Alantic Forest in South-Eastern Brazil, with descriptions of Trichomyia dolichopogon sp. nov. and Trichomyia riodocensis sp. nov," Brazilian Journal of Biology, vol. 61, no. 3, pp. 467-474, 2001.

[39] J. G. C. Hamilton, R. D. C. Maingon, B. Alexander, R. D. Ward, and R. P. Brazil, "Analysis of the sex pheromone extract of individual male Lutzomyia longipalpis sandflies from six regions in Brazil," Medical and Veterinary Entomology, vol. 19, no. 4, pp. 480-488, 2005.

[40] J. G. C. Hamilton, R. P. Brazil, E. D. Morgan, and B. Alexander, "Chemical analysis of oxygenated homosesquiterpenes: a putative sex pheromone from Lutzomyia lichyi (Diptera: Psychodidae)," Bulletin of Entomological Research, vol. 89, no. 2, pp. 139-145, 1999.
[41] M. R. V. Sant'Anna, B. Alexander, P. A. Bates, and R. J. Dillon, "Gene silencing in phlebotomine sand flies: xanthine dehydrogenase knock down by dsRNA microinjections," Insect Biochemistry and Molecular Biology, vol. 38, no. 6, pp. 652-660, 2008.

[42] R. Reithinger, C. R. Davies, H. Cadena, and B. Alexander, "Evaluation of the fungus Beauveria bassiana as a potential biological control agent against phlebotomine sand flies in Colombian coffee plantations," Journal of Invertebrate Pathology, vol. 70, no. 2, pp. 131-135, 1997. 

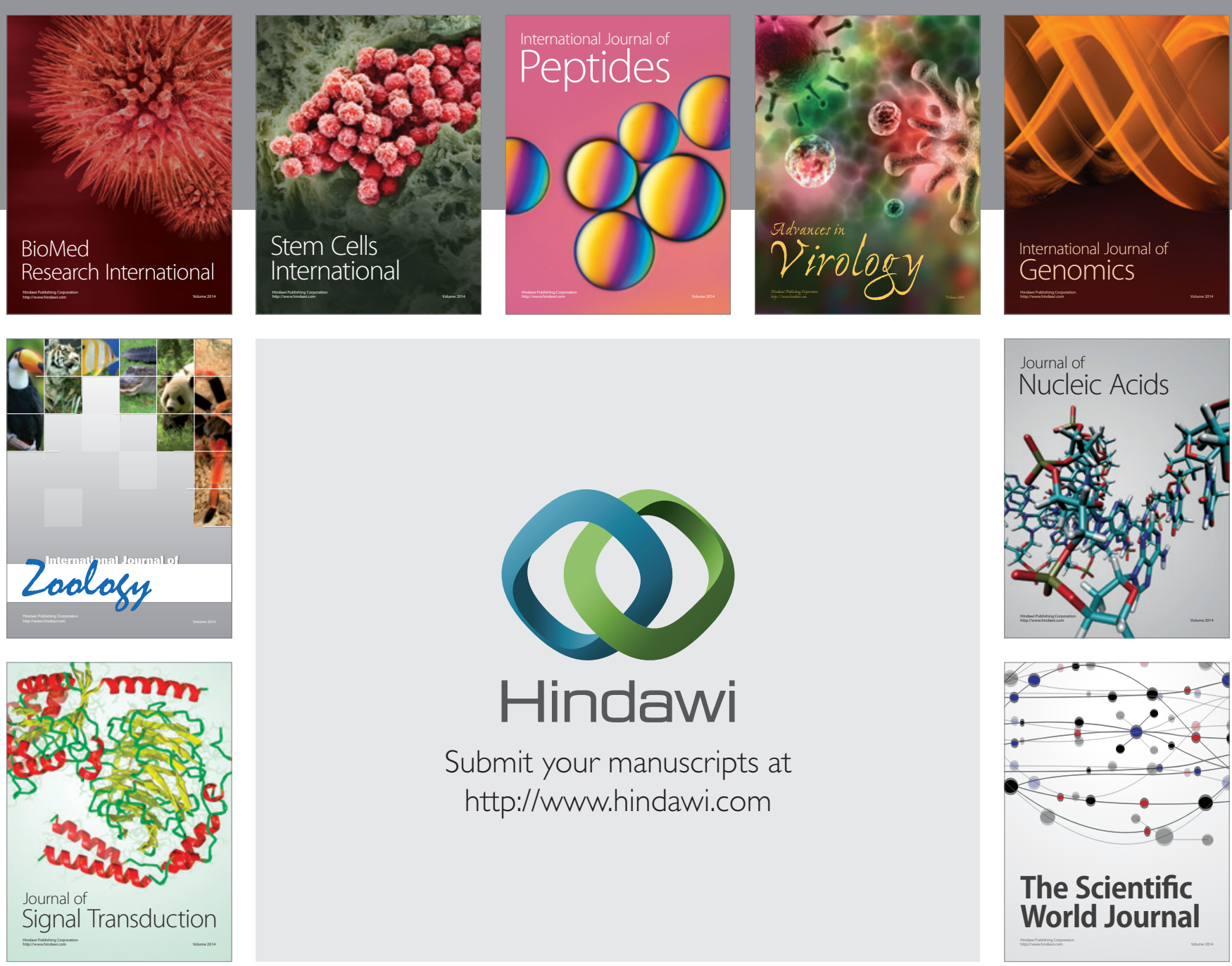

Submit your manuscripts at

http://www.hindawi.com
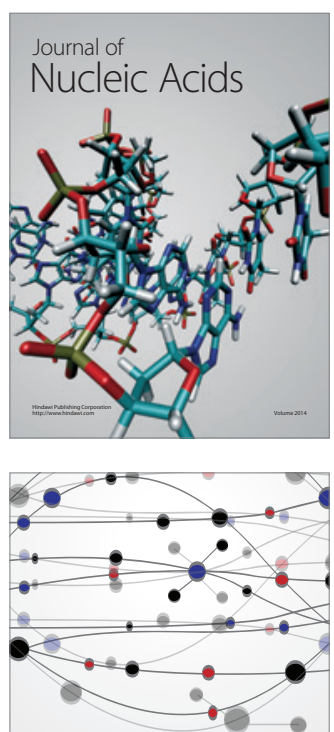

The Scientific World Journal
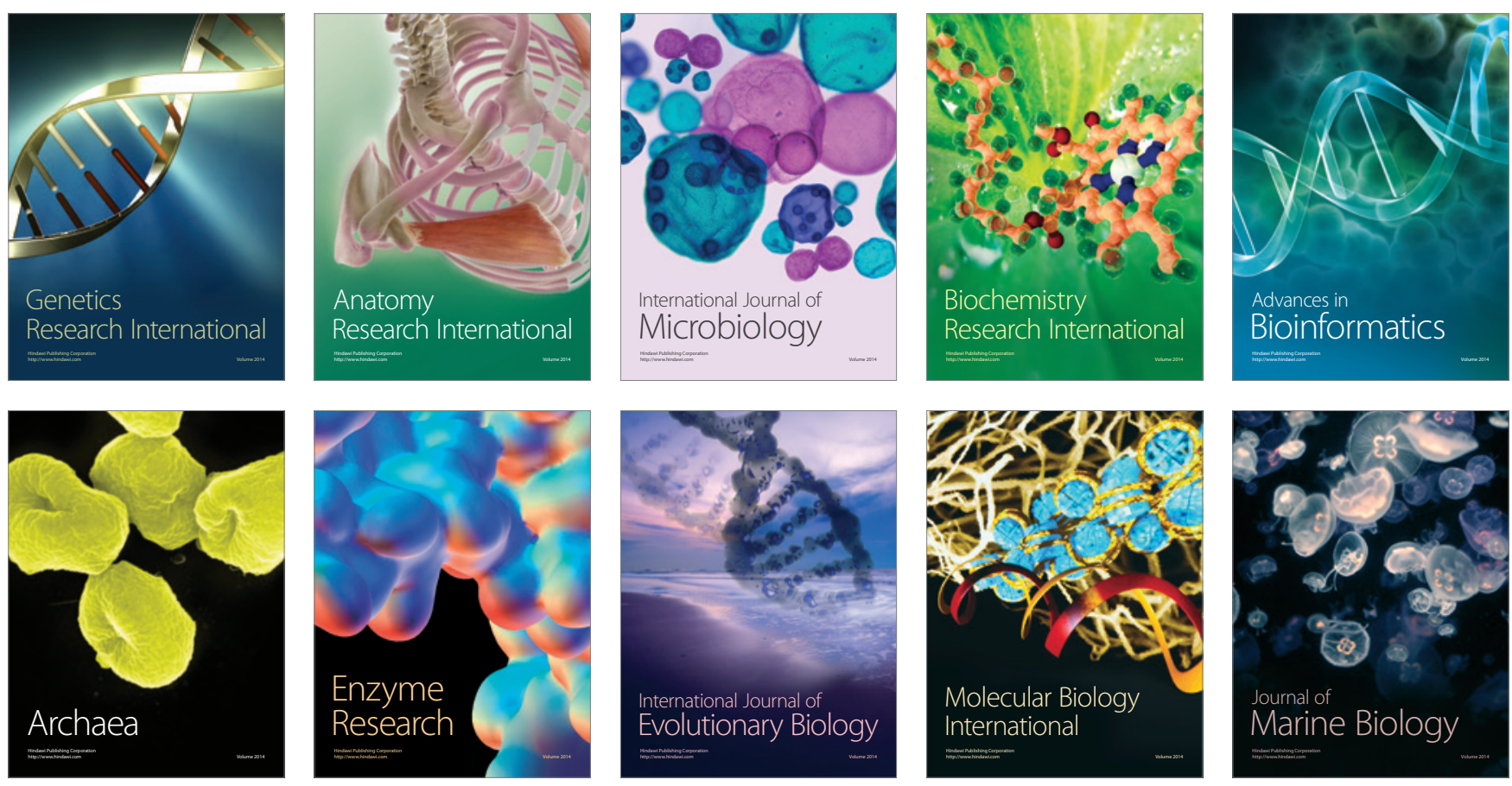